\title{
Uterine artery embolization: the only life saving measure in some obstetric cases
}

\author{
Asha N. Gokhale ${ }^{1}$, Latika J. Chawla ${ }^{2 *}$, Shridhar Khajindar ${ }^{3}$ \\ ${ }^{1}$ Consultant, ${ }^{2}$ Resident, Department of Obstetrics and Gynecology, Deenanath Mangeshkar Hospital and Research \\ Centre, Pune, Maharashtra, India \\ ${ }^{3}$ Consultant, Department of Radiology, Deenanath Mangeshkar Hospital and Research Centre, Pune, Maharashtra, \\ India
}

Received: 29 September 2015

Accepted: 01 November 2015

\section{*Correspondence:}

Dr. Latika J. Chawla,

E-mail: latika_24@hotmail.com

Copyright: ( $\odot$ the author(s), publisher and licensee Medip Academy. This is an open-access article distributed under the terms of the Creative Commons Attribution Non-Commercial License, which permits unrestricted non-commercial use, distribution, and reproduction in any medium, provided the original work is properly cited.

\section{ABSTRACT}

Uterine artery embolization is a highly specialised and efficacious method that can be used prophylactically to reduce obstetric haemorrhage. Its use in modern obstetrics is currently limited to morbidly adherent placenta and acreta. This report presents a case where uterine artery embolization has been used as the primary treatment for obstetric haemorrhage in a patient with high risk for PPH where surgical management would not have been possible. We aim at highlighting the benefits of this procedure in terms of reduced surgical blood loss, morbidity and fertility preservation.

Keywords: Embolization, Obstetric haemorrhage

\section{INTRODUCTION}

Since the advent of modern medicine, obstetrical haemorrhage has been one of the most dreaded complications in pregnant women. Traditionally, medical methods like utero - tonic agents have been used to treat obstetric haemorrhage, which when persistent and severe, requires surgical interventions like selective artery embolization and lastly, hysterectomy. Pelvic artery embolization was first described by Brown et al in 1979. Over the last three decades, this method gained popularity as a fertility preserving technique with good success rates. It has been predominantly used as a prophylactic technique for cases of morbidly adherent placenta. We present a case of complete placenta previa with previous LSCS and abdomino - perineal surgery with dense adhesions where uterine artery embolization was used as the first line of treatment anticipating the difficulty in surgical management of postpartum haemorrhage in this high risk case.

\section{CASE REPORT}

A 38 year old female, gravida 3 para 1 living 1 abortion 1 , with previous one lower segment caesarean section presented in the antenatal OPD at 38 weeks of gestation. Her obstetric ultrasound at this gestation was suggestive of grade 4 (complete) anterior placenta previa. Ultrasound Doppler was done to rule out the possibility of an adherent placenta. There was no evidence of an adherent placenta on the Doppler study.

Our patient had a significant past surgical history. She had a history of recto - sigmoidectomy with an abdominal - perineal pull through 14 years back. She delivered her first child by a caesarean section. Going through the intra- operative findings of the previous caesarean, we learnt that there was difficulty in approaching the uterus due to dense adhesions between the anterior abdominal wall and uterus and that she had sustained bladder injury in the above said surgery which was corrected intra-op.

In view of her surgical history along with complete placenta previa in the current pregnancy, an elective 
repeat caesarean section with pre - operative uterine artery catheterisation was planned for this patient.

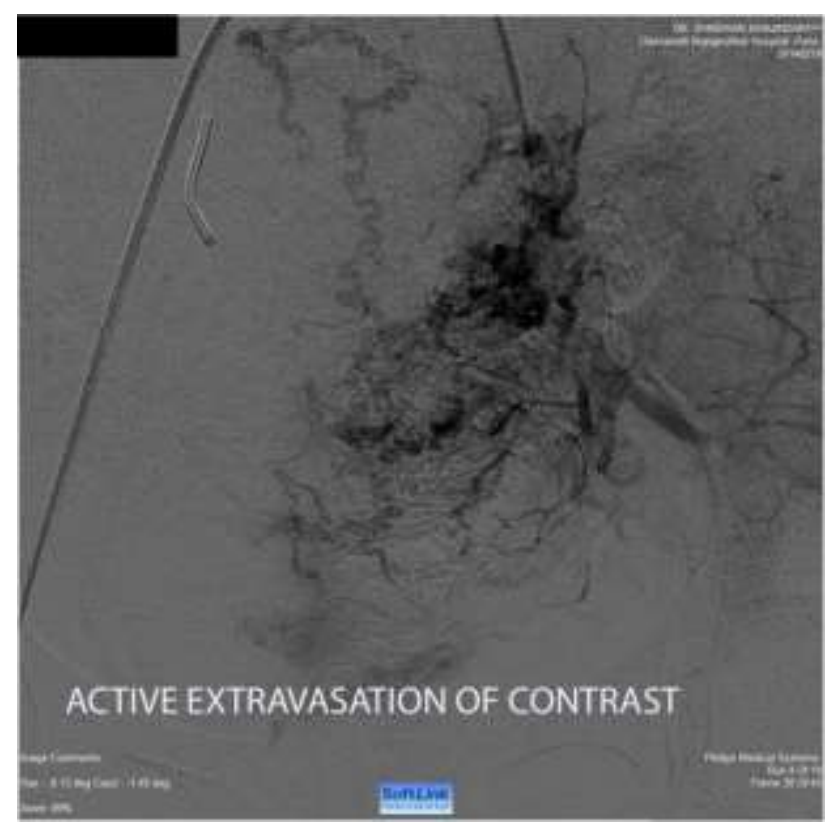

Figure 1: Post caesarean extravasation of contrast seen at the anterior division of left sided internal iliac artery.

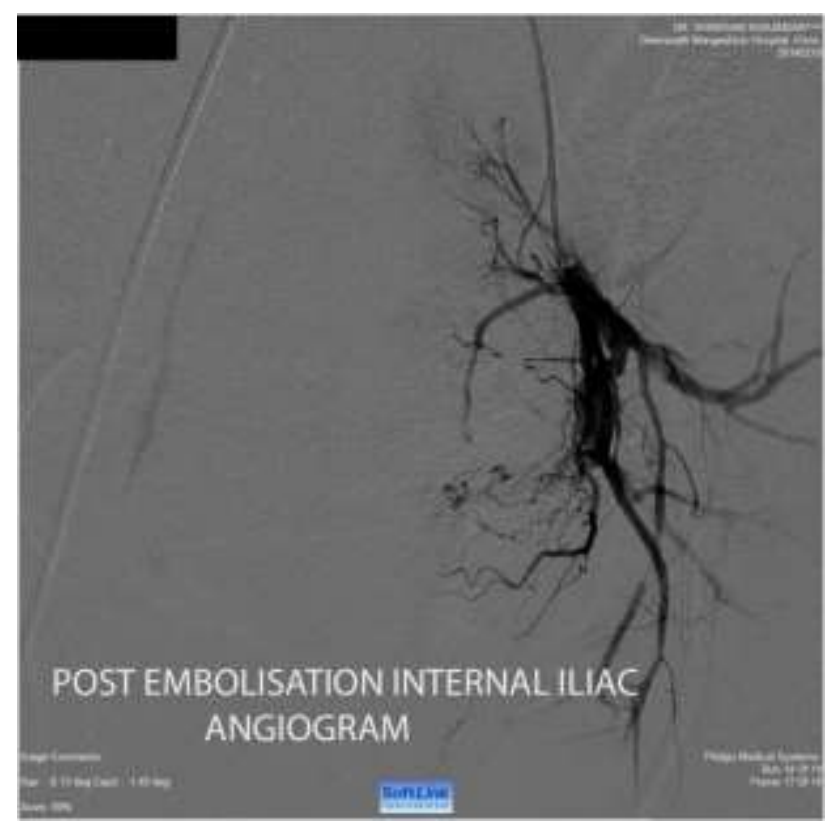

Figure 2: Post embolization check of the left internal iliac artery.

Bilateral uterine artery balloon catheters were placed by transcutaneous femoral approach under local anesthesia on the operating table by our Interventional radiologist. After which, spinal anesthesia was given and caesarean was commenced. Intra operative, the bladder was completely adhered to the lower uterine segment. A low upper segment transverse incision was taken through the anterior placenta and baby was delivered. Soon after the delivery of the baby, the uterine artery balloons were inflated which significantly reduced bleeding at the site of incision. The surgery was uneventful. Immediate post op the patient was shifted to the catheterisation- lab where fluoroscopy was done and, hyper vascularity was observed close to the anterior division of the left sided internal iliac artery (Figure 1). Hence selective embolization of the above said artery was done (Figure 2).

Surgical blood loss was $800 \mathrm{ml}$. Patient tolerated the surgery well and the post-operative period was uneventful. Post-operative haemoglobin was 10 gram $\%$ and she was discharged on day 4 on oral haematinics.

\section{DISCUSSION}

Postpartum haemorrhage is the most dreaded complication in obstetrics. Blood loss is often underestimated and can lead to sudden deterioration of the patient. Hence, the concept of "The Golden Hour" has been put forth, one that clearly emphasizes the importance of early intervention to reduce maternal mortality. Despite the various advantages of pelvic artery embolization, it has largely been ignored in management of obstetric haemorrhage. Even though uterotonic agents, uterine tamponade and internal iliac artery ligation have been used widely, they can have a failure rate as high as $50 \%^{1}$ and can lead to a more radical procedure, hysterectomy. Obstetric hysterectomy is the final approach but has the biggest disadvantage of loss of future fertility for women in the reproductive age group. Risk of general anaesthesia, surgical blood loss and intraoperative difficulties further increase the morbidity. On the other hand, all the above problems can be avoided by performing a pelvic artery catheterization. Almost all women resume menstruation after this procedure and successful pregnancies also have been reported. ${ }^{2}$ The success rate of this interventional method is higher $(>90 \%)^{1}$ than that of arterial ligation and its failure, if any, can be followed by a hysterectomy but not vice versa. Especially in the above case, where approach to the retro peritoneum would not have been easy considering the loss of normal anatomy and adhesions due to previous surgeries. Complications like reactionary fever, buttock numbness and non-target embolization have an incidence around $6 \%$ to $7 \%$. $^{1,2}$

Catheter placement under fluoroscopic guidance has led to the concern about foetal radiation exposure. According to the International Commission on Radiological Protection, many pregnant women are unintentionally exposed to radiation in early pregnancy and the risk may hence be over and above the standard $3 \%$ risk of malformation, unrelated to radiation. ${ }^{3}$ Endovascular techniques can deliver around $100 \mathrm{mGy}$ which does increase the teratogenic risk in the first trimester of pregnancy. Though, in later gestation, stochastic effect of radiation is a concern, there is no standardization of the radiation level at which this effect is eliminated. Use of 
lead shields, reducing the rate of pulsed fluoroscopy, limiting magnification and using tight collimation are among the many methods used to reduce the foetal exposure. Pre-operative placement of catheters have been associated with an increased risk of exposure to foetus, hence some authors have tried rapid catheterization by an expert radiologist at the onset of $\mathrm{PPH} .{ }^{4}$ This approach does help reduce radiation exposure to the foetus but can be tricky. Quick catheterization even by an expert at the time of panic might not always be possible leading to excessive blood loss requiring massive transfusion of blood and blood products and an increase in the rate of infection, thereby increasing the morbidity of the patient. Whereas in our case, preparing the patient prior to surgery, made it easy to operate as well as reduced her post-operative morbidity significantly. Hence, each case must be individualized and benefit and risks weighed.

In a set up where facilities for endovascular catheterization are available, pelvic artery embolization can be a boon to a patient who is high risk for PPH and wishes fertility preservation. In the hands of a skilled interventional radiologist, it can be used as the procedure of choice in this setting.

Funding: No funding sources Conflict of interest: None declared

Ethical approval: Not Required

\section{REFERENCES}

1. Hansch E, Chitkara U, McAlpine J, El-Sayed Y, Dake MD, Razavi MK. Pelvic arterial embolization for control of obstetric hemorrhage: a five-year experience. American journal of obstetrics and gynecology. 1999;180(6):1454-60.

2. Banovac F, Lin R, Shah D, White A, Pelage JP, Spies J. Angiographic and interventional options in obstetric and gynecologic emergencies. Obstetrics and gynecology clinics of North America. 2007;34(3);599-616.

3. Moon EK, Wang W, Newman JS, Bayona-Molano. MDP. Challenges in Interventional Radiology: The Pregnant Patient. InSeminars in interventional radiology. 2013;30(4):394.

4. Lim HJ, Kim JY, Kim YD, Park JY, Hong JS. Intraoperative uterine artery embolization without fetal radiation exposure in patients with placenta previa totalis: Two case reports. Obstetrics \& gynecology science. 2013;56(1):45-9.

Cite this article as: Gokhale AN, Chawla LJ, Khajindar S. Uterine artery embolization: the only life saving measure in some obstetric cases . Int $\mathbf{J}$ Reprod Contracept Obstet Gynecol 2015;4:2093-5. 